\title{
The Role of New Technologies in Value Co-Creation Processes: Healthcare Management and the National Health System as a System of Services
}

\author{
Armando Masucci $^{1}{ }^{\circledR}$, Antonietta Megaro $^{2 *}$, Carlo Alessandro Sirianni2 \\ ${ }^{1}$ Pegaso University, Naples, Italy \\ ${ }^{2}$ DISA-MIS Department, University of Salerno, Fisciano (SA), Italy \\ Email: amasucci@unipegaso.it, ^amegaro@unisa.it, carlo.sirianni@unisa.it
}

How to cite this paper: Masucci, A., Megaro, A., \& Sirianni, C. A. (2021). The Role of New Technologies in Value Co-Creation Processes: Healthcare Management and the National Health System as a System of Services. Journal of Service Science and Management, 14, 189-212.

https://doi.org/10.4236/jssm.2021.142012

Received: March 2, 2021

Accepted: April 25, 2021

Published: April 28, 2021

Copyright $\odot 2021$ by author(s) and Scientific Research Publishing Inc. This work is licensed under the Creative Commons Attribution International License (CC BY 4.0).

http://creativecommons.org/licenses/by/4.0/

\begin{abstract}
Technologies may affect the emergence of value co-creation phenomenon within the national health system. The aim is to explore how the exchange of resources between actors connected through multi-level relationships, whose interactions are mediated by technology, can lead to the joint creation of new value and potential innovation. By analyzing the definition of value co-creation, the paper presents the National Health System as a complex service system and proposes a conceptual framework, then applied to the case study to identify: 1) the enabling factors for value co-creation; 2) the network mechanisms and the information interests of the various actors that lead to the continuous renewal of resources, to value co-creation and to innovation. Results allow the conceptualization of the enabling factors for co-creation management and guide managers to identify tools, resources, and technologies that promote value co-creation by improving understanding of the different types of activities performed by actors during the joint exchange of resources and the mechanisms that promote the active involvement of users and patients.
\end{abstract}

\section{Keywords}

Value Co-Creation, Technology, National Health System, Network, Service System

\section{Introduction}

Value co-creation is the phenomenon through which contemporary manage- 
ment and marketing studies reinterpret the processes of value exchange and diffusion among the actors involved in its generation process, primarily understanding value as a common (sometimes even collective) benefit obtained through intense collaboration between the parties (Payne et al., 2008). Co-creation, by definition, involves the active role of all involved elements, including end-users, in constant collaboration with each other for the continuous release of resources, strategic sharing of information and goals, and increasing mutual satisfaction. In line with the recent conceptual changes, found in terms of definition and interpretation on service-related aspects, a new framework, a new scientific culture, a new form of thinking has emerged in the last decade: The Service Dominant (S-D) Logic (Vargo \& Lusch, 2004). The S-D Logic is the result of a long and specific cognitive path, historically well-recognizable and based on fundamental pillars such as customer-oriented perspective, market-determined value (Levitt, 1981), Total Quality Management and service organization (Gummesson, 1993).

The S-D Logic accounts for new and more modern management techniques inside and outside the company and completely reinterprets the concept of service (Vargo et al., 2018), coming to define the logic of production and market exclusively through the service-centred paradigm (Lusch et al., 2007). From this point of view, the interpenetration of needs, resources, information and objectives fuels between suppliers and recipients a process of value co-creation (Tommasetti et al., 2017) that leads to the strengthening of a lasting and sustainable competitive advantage. The reinterpretation of the processes of co-creation of value in a service-dominant perspective allows to explore not only the complex mechanisms of exchange of resources that underlie the provision of services, but also the co-development of new knowledge, new rules and socio-cultural practices. Therefore, the adoption of S-D logic is essential to investigate the joint generation of value in service contexts. In particular, the health system, composed of a complex network of actors that are configured in different ways as useful resources that must necessarily participate in the efficiency and effectiveness of the service and, therefore, the overall performance of the system itself, lends itself to a reinterpretation in key service-dominant (Vargo \& Lusch, 2017). The effective and real interaction between various operators, companies and the community in the health sector necessarily infers the participation of the various actors mentioned within the process of generating a sustainable value for the benefit of all.

Such dynamics of synergistic value generation make the healthcare system observable as a complex service system (Maglio \& Spohrer, 2008). A key step in healthcare management is the application of new technologies to support development on advanced technological solutions that facilitate the exchange of resources internally and externally, enabling value co-creation processes. Thanks to Information and Communication Technologies (ICT), technology platforms in healthcare encompass people, processes and knowledge thus achieving scope alignment (Crespo Garrido et al., 2017) as well as reduced coordination and 
transaction costs among stakeholders (Baldwin et al., 2000). It is also widely recognized in the literature that there is an influence between the adoption of new technologies, the co-creation of value (Polese et al., 2020b) and the potential development of new value and, therefore, innovation (Barile et al., 2020). However, in literature it has not been detailed enough as these technologies can affect the co-creation of value in the healthcare system, considered as a service system, enabling health actors to integrate resources in an effective and sustainable way. Thus, this paper investigates the processes of value co-creation in the healthcare public sector (Tommasetti et al., 2020), imagining health and its protection as the main and priority value for each community, and exploring the key role played by new technologies in the dynamics of joint development of value. This contribution aims to deepen the theme of the service in health, in order to understand the actual orientation of the most important players (actors) operating in the sector today, with particular emphasis on the concepts of co-creation of value, innovation (in the service), value that represent the basis for a growing phenomenon called patient empowerment. The study seeks to understand how value is co-generated in the healthcare setting by investigating: 1) the role of the actors and the joint mechanisms of resource exchange within the system; 2) the role of new technologies as an enabling factor of value co-creation. Methodologically, the work uses the framework of Service Research as a conceptual basis, with a particular reference to the paradigm of S-D logic. By analysing the National Health System (NHS) as a system of service, it is possible to identify several elements of co-creation of value, intrinsic, governable, implementable. The network of actors within the health network indeed appears instrumental to the governance of instances through reticular logic to support the co-creation of value. The study, therefore, observes the NHS as a network of connected and interacting actors, aiming, through processes of co-creation of value enabled by the use of new technologies, to pursue public health. The proposal of a framework that identifies the main actors involved, the exchanged resources and the technologies used for interaction can provide a valuable support to managers of the health sector who want to understand how to achieve a conscious and efficient use of new technologies, exploiting the countless opportunities for co-creation enabled by them.

To sum up, the research structure provides an initial description of the theoretical framework (par. 2) in which it puts the attention on value co-creation, new technologies as enabling factors for the value co-creation (par. 2.2) and the theoretical description of the the National Health System (2.3). Subsequently, a reinterpretation of the NHS intended as a service system is proposed (par.3), to investigate processes and mechanisms mediated by new technologies that lead to the co-creation of value in the health sector (par.4) and a possible technology infrastructure for value co-creation in healthcare (par. 4.1). The work concludes with a discussion on all the topics (par. 5) and final considerations, practical managerial implications (par. 6). 


\section{Theoretical Background}

In order to answer the research questions presented above, this section presents a brief theoretical overview of the themes of value co-creation (section 2.1), of the role of technology as an enabling factor (section 2.2), and of the national health system, reinterpreted as a system of services (section 2.3).

\subsection{Value Co-Creation}

The foundations of Service Research and System Thinking promote the concept of co-creation of value, considering the end user not as a simple external component of business processes and commercial interactions, but rather as a crucial actor in organizational and production processes, and, therefore, able to contribute effectively to create a sustainable competitive advantage. This vision integrates the contributions of several parties (Womack et al., 2007) allowing the sharing of insights, needs, resources, enhancing the relational approach (Gummesson, 2011) and the systemic approach (Barile, 2009) for the entire network and its management (Pellicano et al., 2018). According to the S-D logic, consumers are always co-creators of value, before the consumption process (and therefore of an implicit acceptance of the value propositions advanced and present on the market) we cannot even talk about value (Troisi et al., 2017). It results from the beneficial application of the operating resources and also involves tangible advantages to third parties interested and, therefore, inevitably involved in the process of creation. In fact, value represents what one is willing to give up in exchange. In order to obtain something of real value for oneself, one may be willing to give up a large number of resources (e.g., their time, money, work performed, etc.); the measure of this trade-off of choice is represented by value (Prahalad, 2004). From this perspective, the value proposition ultimately represents a specific package of benefits and solutions that a service system intends to offer and provide to others. The division of labor lays the foundations for many value propositions; thus, the modern meaning of service can be associated with a form of value co-creation that involves both parties in an exchange (Pels et al., 2012). On closer inspection, no socio-economic actor succeeds in autonomously providing value for the interlocutor (Lovelock \& Gummesson, 2004). The different actors are in fact involved, in a more or less conscious way, in the exchanges of value with other actors, and, in this process, they activate more or less satisfactory interactions, linked to more or less fruitful paths of co-creation of value within networks between actors (Jaakkola \& Hakanen, 2013). When we move away from the product/service centric view of value creation, which has been the dominant logic in marketing and business strategy so far, and toward an experiential view in which value co-creation is at the center, new and enlightening perspectives open up (Prahalad \& Ramaswamy, 2004). The focus of value creation and above all of value co-creation must, hence, necessarily be deepened both internally (through strategies for improving the quality of goods and services and structural growth in terms of skills, knowledge and 
opportunities) and externally (because of collaborative relationships with other players involved). The re-conceptualization of the value chain in the context of networks, on the other hand, explains how the competitive advantage can be referred not only to the connections between the individual nodes, but also to the ability of each actor to reconfigure its structure in accordance with the changing competitive strategies and those of other actors, in a co-makership logic, systemic in nature. The value chain of today, therefore, is actually a system of value creation, built around a culture of service, rooted in the logic of co-creation, based on networks of multiple chains (networks of networks), in which capabilities, interests and needs of each actor, are placed to the advantage of the whole, causing the empowerment of each of its participants (systemic culture). It is therefore useful to reiterate that the consumer does not directly obtain value from the product itself, but from its use, transformation or consumption (Vargo \& Lusch, 2008a) and from its comparison with other entities interested or involved in the generation process; the value of a product therefore derives from the benefit obtainable from the underlying service. By breaking down the phases of this process, it is possible to identify aspects that are not always adequately valued. According to this new interpretative approach, consumers are no longer seen exclusively as a target clientele to which to submit their own varied offerings; today (as it will be discussed in more details below), entrepreneurial organizations can only formulate their own value proposition; consumers are considered effective productive factors and co-creators of value, within a complex system of service provision (the service system), capable of benefiting not only from the purchase of products available on the market, but also and above all from their transformation, use and consumption, increasingly revealing their active role in the generation process (consumers as participants). The value is therefore determined by the consumer at the time of purchase, through a personal process of consumption, favored by the constant interaction with the other parts of the service system in which it operates (Maglio \& Spohrer, 2013). This process allows the perceived value, up to that moment (i.e., before being enjoyed), to be made effective, in fact only a potential proposed value. The customer therefore becomes the irreplaceable co-creator of value and the company is consequently observed as the integrator (and manager) of the resources necessary for the creation process (Polese et al., 2017a).

There are also many more stakeholders involved in these types of processes, although it is not always easy to see/verify. From this point of view, customer satisfaction and competitive performance in business are considered cyclical, targeting suppliers, producers, customers, consumers. On the basis of these considerations, each of these participants can be considered as a partner in previous processes and a promoter of subsequent ones; therefore, suppliers can become sub-suppliers, producers can represent co-suppliers, customers can appear as co-producers and consumers as prosumers, contributing to a new vision of business activities analyzed according to different organizational and managerial 
perspectives.

\subsection{New Technologies as Enabling Factors for the Value Co-Creation}

Often it happens to stumble in the search for medical information and to solve the problem independently. This anomaly seems to be able to be resolved through a few targeted interventions with the sharing of patient information. It is necessary to organize the health services of the citizens of our country more functionally concerning the different needs of users and the resources available. Smart eHealth solutions can support this re-organization and have to be designed and tested.

The widespread use of digital technologies has improved the knowledge of the behaviour of individuals involved in a complex system (Troisi et al., 2018b), thus increasing smart interaction about the exchange of service (Polese et al., 2020a). The deriving evolutions in terms of reconfiguration of the interactive system have modified market dynamics with new service and value meanings. The interactions, exchanges, services, entities of a system depend on data. Data are elementary elements that must be interpreted to provide knowledge if correctly interpreted within a knowledge domain (Troisi et al., 2018a). Once the data have allowed the creation of knowledge, it's possible to provide understanding and prediction for other knowledge, thus following the hierarchical model called Data, Information, Knowledge and Wisdom (Cooper, 2014), and possibly work on structured data with algorithms and automatic methods of inference and learning. The basic logic of the project is a service eco-system perspective that places the patient (seen as one of the many types of users/actors) at the centre of a network of relationships and information flows related to the various health services. The relevant information in the process/functioning of the NHS are, in fact, numerous, so it becomes essential to be able to access them in a simple and functional way. Thinking of the interaction process between user/patient and local pharmacies for the purchase of drugs: from simple real-time information about the drug available to more important information, such as any contraindications or reporting of adverse reactions, which is essential for pharmacovigilance activities. A real registry of services and users would facilitate the interactions between actors of the system in which the active role of the end-user is fundamental, in fact, according to this perspective it is the patient who networks and participates. Health information systems support planning and control at both national and regional levels, facilitate assistance in the relationship between citizen and general practitioner, and improve the delivery of services. Information systems have the merit of disseminating knowledge, sharing progress, allowing real-time feedback, and making information accessible to all stakeholders. Information systems respond to the need for data management mentioned earlier. Healthcare information systems in Italy have developed along two main lines: 1) computerization of control flows at national and regional level; 2) 
computerization of the provision of services in healthcare companies. As a result of the renewal process of our NHS, one of the most developed tools has been the Health Information System (HIS), whose purpose concerns the support of management activities in terms of general and analytical accounting, as required by the regulations. The clinical activity is characterized by multidisciplinary and multiplicity of actors, by a high information need and the need to share information (among doctors, nurses, specialists, general practitioners, family members) even if fragmented and/or written on paper. Healthcare facilities are moving towards the digitization of personal information, the interoperability between systems (for a unique recognition of the patient) and the computerization of the Clinical Record (higher quality care, possibility to consult diagnoses and tests performed during hospitalization and also to access the entire medical history of the patient). The contribution that information systems make to foster the centrality of the patient in the care pathway is fundamental. The system becomes concretely patient-centric, with the design of the pathways, the articulation of its actors, their respective roles, the mechanisms of interaction and coordination. Each patient has his own pathway, each pathway has its own cost, the SIS makes it possible to combine the economic valorization of the pathway and thus favors the personalization of the Service.

Through the adoption of Activity Based Costing (ABC), it is possible to define the resources adopted by each activity, allowing to evaluate the overall cost of the patient's path. Investing in information systems, therefore, can not only allow the improvement of the efficiency of the system, promoting a better synergy between the various operators and a reduction of redundancies and duplications, but, above all, can help the health system, thanks to a more effective coordination, to improve the quality of services for patients and be closer to them.

\subsection{The National Health System}

At local, regional and national levels, there is a growing consensus that public health is in crisis due to the increase of population's average age, rising costs and decreasing financial resources allocated to health. Nevertheless, the international literature is not dedicating enough attention to the co-creation of value in health care, as a methodological response, or at least interpretation, to the provision of services in complex contexts, such as health care. In particular, within the NHS, analyzed as a system, it is possible to identify several elements that support its interpretation from the perspective of co-creation of value: We can say that, in general, all actors in the NHS are involved in the process of care and in promoting instances of improvement (Sweeney et al., 2015). The effectiveness of this process is closely related to the interaction and cooperation between these actors, who seem to be linked by strong coordination mechanisms at various levels, operational, political, social, economic, ethical, and legal. The provision of health services represents a set of central activities in the social context because, through the provision of preventive, diagnostic, treatment, care and rehabilita- 
tion services, they allow the pursuit of the ultimate goal of any health system, the welfare of the population and public health. The considerable relevance of the subject, supported by the ethical-social purposes that the healthcare system ultimately assumes, make it an important area of analysis in business studies in general, and in management in particular, in view of the importance of the economic activities developed by the many actors involved in the provision process. Moreover, in the last decades, the sector has been characterized by strong changes that have modified, over time, its political-institutional structures, its functioning, its organization at a territorial level, the relationships between actors, which, in turn, have been subject to changes in form and type. Moreover, among the players, trends have emerged that have favored market logics, connoting the sector from competition mechanisms typical of other industrial and/or service sectors. These changes have stimulated over time the public and private players in the healthcare sector to an evolution of the underlying logic, to a change in operation, in search of new, more competitive organizational models. In order to effectively address these competitive innovations, the need has arisen for new models of analysis of the health phenomenon, for theoretical and possibly managerial insights, capable of guiding the observer, or the manager or the simple operator, to a greater understanding of the intrinsic complexity of the system. Healthcare organizations do not produce a tangible good but a service: The care and protection of collective health. The work they do is not aimed at the production of a simple product, but rather at the affirmation of a collective orientation such as healthcare as a public value. This orientation, in the same way, necessarily infers the involvement, responsibility and awareness of everyone, from professionals to patients and citizens. Therefore, we move from the concept of a healthcare system that provides assistance to that of a community that contributes to this process, assuming responsibility for it. In other words, in recent decades, we have witnessed the passage (at times incomplete) from the provision of parcelled-out services to the creation of shared paths between the various healthcare professionals and between these and the users. In this perspective, it is essential to build a common sense of medicine, which allows all individuals to take ownership of a topic that has implications in their daily lives and that, therefore, requires a broad verification and acceptance. In addition, the set of health organizations analyzed in a systemic framework can be defined as said an eco-system (Polese et al., 2017b), is part of a broad context that opens its boundaries to the external environment by forming relationships with the various actors that operate in it (Barile, 2009). Through such networks, healthcare enterprises are able to obtain the resources they need and to exchange them within the system they represent and with the environment to generate a sustainable value. This value, possible through the generation of synergies, makes the health system a service system (Maglio \& Spohrer, 2008). The complex organization of the healthcare system, the number of actors, the ambitious pursuit of its goal, public health, stimulates the deepening of the logic that can support 
the generation of value for the different actors involved, and, of course, for the main beneficiary, namely the patient. The pursuit of public health must be organized in a more functional way, to allow the satisfaction of the needs of a diverse set of users, consistent with the availability of resources of the actors involved in the process of service delivery. Solutions should be able to be replicable, scalable and versatile to the most diverse contexts, to be useful. In reality, all innovations are capable of solving specific problems but never applicable to the healthcare network as a whole. Many actors are involved in that complexity, each has priorities and goals, and the organizations are often different. Their interaction is subject to the inevitable differences in language, purpose, and operations.

In order to seriously contribute to the renewal of health service systems, so complex and articulated, and to really support the development of a new governance, modern and efficient, complementary to the products already being implemented, it is possible to propose solutions to embrace all the actors involved.

\section{A Reinterpretation of the National Health System as a System of Services}

The theme of co-creation is relevant in the healthcare sector, as the provision of healthcare services necessarily requires the active participation of the various stakeholders. The value generation process respects a win-win logic in which interactions and the collective good prevail over individual choices and single interest. The (always voluntary) exchange of resources, skills and information encourages value co-creation processes, stimulating the creation of increasingly intelligent and adaptive service-oriented value systems. The service nature of the healthcare system allows us to state that the logic focused on the service finds its ideal position both in the theoretical and managerial healthcare fields, helping to define efficient paths for the generation of value, which, in the healthcare field, is mainly represented by health. In a service logic the final co-created value of health comes from shared activities. All the actors involved can be considered, at the same time, as dynamic resources, active, working and, therefore, sources of competitive advantage for the health organization, as well as sources of value and innovation for the entire health system. The processes and functions, often aimed at reducing costs, have been considered purely for the benefit of governments or health structures, with relative reduced opportunities for the recipients of the value propositions. From this perspective, the Value Proposition represents a specific package of benefits and solutions that a service system intends to offer and provide to others. The division of labor is at the root of many value propositions; hence, the modern meaning of service can be associated with a form of value co-creation involving both parties to an exchange. In activities linked, for example, to self-service, the desire to acquire the knowledge necessary to carry out a given task, which brings a direct advantage to those who carry it out (in accordance with an operational protocol and with a standard of result that can be compared), in itself already represents a concrete form, and long 
established, of convergence of demand towards a collective action, a true activity of co-production (and therefore co-creation). Moreover, the ubiquity of connectivity facilitates customers to be well informed and related in a global network, where the convergence of technologies and information sharing are present. As a result:

- Users (patients) are not isolated; users, user communities, and businesses interact all the time; communities can be integral to value creation processes.

- The outcome is a co-creation of value; what is created is an experience. Physical products and services can be the artifice around which personalized experiences are co-created.

- New elements of value co-creation are always needed, such as two-way dialogue, information access and transparency (to eliminate information asymmetry between business and customer), and risk assessment (between consumers, their communities, and businesses).

As a result, no single organization (part of the service eco-system studied) can provide a complete co-creative experience on its own. Often a network of businesses must act together to provide a unique co-creative experience (Gummesson, 2008). When we move away from the product/service centric view of value creation, which has long been the dominant logic in marketing and business strategy, and toward an experiential view in which co-creation of value is at the center, new and enlightening perspectives open up (Ramaswamy \& Ozcan, 2018). In summary, the contribution of value co-creation processes to understand the dynamics of the NHS is detailed below in Table 1.

The goal of value co-creation, in fact, must be both internal (through services and strategies to improve product quality, optimize effectiveness and efficiency) and external (as a function of collaborative relationships with other virtual actors, seeking structural growth in terms of skills, knowledge, technical opportunities,

Table 1. Value co-creation for the study of national health system dynamics.

\begin{tabular}{|c|c|c|}
\hline Theory & Focus & Interpretive contribution \\
\hline Value & $\begin{array}{l}\text { - Subjective aspect. } \\
\text { - Something to defend or obtain. }\end{array}$ & $\begin{array}{l}\text { In Health Care the absolute value is represented by Health, which is subjectively } \\
\text { understood by each patient, but represents a common good to be protected and possibly } \\
\text { treated in an increasingly effective way. It is something that must be defended because it } \\
\text { cannot be duplicated, it cannot be replaced; it is the most precious good, the most } \\
\text { important thing in a Community. }\end{array}$ \\
\hline $\begin{array}{l}\text { Multi-part } \\
\text { contribution }\end{array}$ & $\begin{array}{l}\text { - Nonlinear processes. } \\
\text { - Spirit of aggregation for common } \\
\text { purposes. }\end{array}$ & $\begin{array}{l}\text { In healthcare, due to the collective importance attributed to health, and the widespread } \\
\text { possibility of contributing to its protection, and also given the systems approach of } \\
\text { healthcare organizations, it is easier to understand how the NHS works and how it is } \\
\text { structured to aggregate (in a non-sequential and reticular manner) different actors based } \\
\text { on their own specific resources. }\end{array}$ \\
\hline
\end{tabular}


and so on). The patient is therefore a relevant actor in the value co-generation process that needs attention. Modern health systems must involve citizens and patients to participate in the processes of prevention, treatment, rehabilitation, increasing their direct responsibility for the operation because the relevant and common goal is human health. Some empirical studies have shown that the active involvement of patients in various care activities have brought many benefits to patients themselves. The scientific study by McColl-Kennedy et al. (2012) investigated patients' multiple approaches to value co-creation in care activities and it has been shown that patients' quality of life increases when the increase of involvement activities occurs. Therefore, patients' psychological and clinical activities show improvement when patients are involved and aware of the actions and treatments they are undergoing. On the other hand, passive and non-involving care has shown lower results (Jacobson \& Neumann, 2009). Chakraborty and Dobrzykowski (2013) published several papers on value co-creation in healthcare, examining internal competencies and external capabilities.

\section{Processes and Mechanisms of Value Co-Creation Mediated by New Technologies: An Application to the National Health System}

The complex organization of the Italian healtcare system, the number of actors, the ambitious pursuit of its purpose, public health, stimulates the deepening of the logics that can support the creation of value for the different actors involved, and obviously for the main beneficiary, namely, the patient. The pursuit of public health must be organized in a more functional way to allow the satisfaction of the needs of a diverse set of users, consistently with the availability of resources of the actors involved in the process of service delivery. In particular, within the NHS, analyzed as a system, it is possible to identify several elements that support its interpretation from the perspective of co-creation of value:

- in order to carry out their work and achieve their interests, private subjects (clinics, ASLs, AOs, diagnostic centers, laboratories, professionals, pharmacies, pharmaceutical companies) and public ones (Ministry, Universities, hospitals, health service agencies, Higher Institutes, Regions, Provinces) need to be active (and proactive) to propose new solutions, to communicate and disseminate them, to share strategies, interventions, objectives;

- in order to be effective and productive, the same players must necessarily collaborate constantly to increase the level of performance of all, not only their own, and, thus, to promote the growth of the system as a whole;

- sometimes the attempt to pursue individual goals, when being part of a team, also indirectly favors the other players;

- in Europe and Italy, there is an official unified and periodic plan of mediumand long-term objectives in accordance with shared basic principles (White Paper); this is to guarantee the interests and satisfaction of all as much as possible; 
- the Italian healtcare system is universalistic and solidarity-based, and the quality of its offerings depends formally on how well it works in terms of health promotion, resource generation, financing and management.

- the patient is a user of offered services and the first recipient of medical care; at the same time he/she is both user and provider of the same value: health; modern Health Care Systems involve citizens' participation in the processes of prevention, care, rehabilitation, increasing their direct responsibility in the process.

Consequently, it can be hypothesized that, in a more strictly service-oriented logic, the final value of health is co-created through shared activities (Polese \& Carrubbo, 2017), incorporating all the actors of the health networks, which are defined as endogenous to the health service delivery processes. At the same time, the actors involved can be identified as dynamic, active resources, and sources of competitive advantage for the healthcare organization, as well as value and innovation for the entire healthcare system (Lusch et al., 2007). In fact, service research replaces the traditional producer-consumer model. The final value is created by both, producer and consumer, as well as by all actors within the same system. These are resource integrators (Vargo \& Lusch, 2008b). In practice, value is not exchanged, but perceived and thus co-created by the consumer as well, and is realized when the supply is transformed and subsequently consumed. The service results in the mutual satisfaction and benefit of the actors involved. Once this interdependence has been appreciated and shared, it seems inevitable to conceive the health service as the result of collaboration between actors aimed at the creation of a shared value, such as that of public health. Service, thus, is a dynamic system of interacting and interdependent parts that create and deliver value in order to achieve and maintain a sustainable competitive advantage (Ciasullo et al., 2017). Co-creation is the result of interaction mechanisms based on value proposition (Spohrer et al., 2008) in which relationships between systems, based on a win-win logic, are consciously activated to achieve optimal outcomes for all parties involved. Where such relationships exist, there is a network, namely, an organizational model that enables a more effective response to market conditions dominated by uncertainty and complexity (Barile, 2009). Within the health system, each actor must act in a functional and effective way, with respect to their personal objectives, and must contribute to the improvement of the quality level of the service provided by the system as a whole, to the development of new and innovative procedures. The idea of value linked to the concept of health is inevitably subjective. Advances in public health are often hampered by financial problems, limited access to information and coordination problems. Duplication, lack of information or incorrect verification errors are common. Connectivity, real-time assessment, standard metrics and metadatation produce very useful spin-offs in this sense; information becomes fundamental as represented in the following Table 2.

Since these subjects are involved in the processes of health innovation, each 
Table 2. Value co-creation for the study of national health system dynamics.

\begin{tabular}{|c|c|}
\hline Subject & Informational interests \\
\hline Patient & $\begin{array}{l}\text { Provide fast and detailed information about their needs and } \\
\text { conditions }\end{array}$ \\
\hline Doctor & $\begin{array}{l}\text { Acquire the latest updates in care, administrative procedures, } \\
\text { diagnostic and preventive processes in a timely manner }\end{array}$ \\
\hline Pharmaceutical company & $\begin{array}{l}\text { Understand what the real needs of the market are and/or propose } \\
\text { reliable and quality solutions to customers }\end{array}$ \\
\hline Hospital facilities & $\begin{array}{l}\text { Offer the right spaces and adequate professionalism to ensure a } \\
\text { high standard of quality to its users }\end{array}$ \\
\hline University & $\begin{array}{l}\text { Acquire evolving needs from the healthcare context and design } \\
\text { different trainings accordingly }\end{array}$ \\
\hline Ministry of Health & $\begin{array}{l}\text { Define and sponsor viable, accessible, and strategic paths of } \\
\text { operation }\end{array}$ \\
\hline Government & $\begin{array}{l}\text { Encourage integration of the communication system, through } \\
\text { unification of databases, simplification of application and } \\
\text { payment procedures, wide dissemination of information on } \\
\text { financing, etc. }\end{array}$ \\
\hline $\begin{array}{l}\text { Pharmacies, clinics, laboratories, } \\
\text { diagnostic centers and general } \\
\text { practitioners }\end{array}$ & $\begin{array}{l}\text { Communicate in a timely manner with both territorial and } \\
\text { national pharmaceutical distributors and warehouses; seek to } \\
\text { network (especially at local level) }\end{array}$ \\
\hline
\end{tabular}

with different priorities and aims, it is necessary to overcome the discrepancies caused by language, education, culture, aims, before such innovation can be feasible. Collective participation in the process of providing and using a service seems to respect the aforementioned win-win, co-creation, and sustainability logics at all levels. Observing strategies, promotions, conventions and attitudes of modern organizations, the respect of the fundamentals of the Science of Service as a practical concretization of the basic concepts deriving from the fusion of systemic and service theories seems really generalized. Through strategic behaviours of aggregative, integrative and cooperative nature, it is actually possible to perform more efficiently and effectively and to reach objectives with greater satisfaction, especially overall. The reticular approach upholds a global governance that enhances resources and relationships and promotes long-term synergies, which are essential for the survival of a system, especially when analysed within a complex eco-system of reference. The logic of value co-creation is defined in this sense as win-win, that is considered the interaction between different entities represented by various service systems (Troisi et al., 2019b) and the desire to obtain a collective advantage of mutual satisfaction, in which the effective contribution is multiple, integration is maximum, complementarity is fundamental. In fact, win-win relationships develop either through the promotion and maintenance of relationships with stakeholders or the common desire to foster co-creation processes (through non-opportunistic behaviour, enduring relationships and shared values), subtending that "life consists of a network of relationships in which we interact" (Capra, 2002) and that life is a network of relation- 
ships, as is business (Gummesson, 2011). The emergency department of a hospital is one of the departments unanimously seen as critical and complex to govern and manage. Situational emergencies, unplanned interactions based on urgency regimes, the seriousness of some situations, and the need to interact with multiple other hospital departments, make the emergency one a place wherein each operator cannot work effectively if left alone 'with the problem'. As a result, it is clear that in the hospital emergency department no matter how hard one tries to plan a healthy emergency management from a preventive perspective, exposure to contextual and emerging factors are always around the corner. A value co-creation collaborative pattern may determine conditions for quality improvement of services provided. All actors involved are willing to participate in sharing their own resources.

From this point of view, it is not important to qualify the players involved, it is worth highlighting the role of relationships and common interests that foster collaborative relationships and the achievement of a common satisfaction.

\subsection{Technology Infrastructure for Value Co-Creation in Health- care}

Technological innovation is a phenomenon that affects many types of companies belonging to different production sectors: from manufacturing to services, both public and private (Troisi et al., 2021). One of the most evident aspects of this phenomenon is the investment in the purchase, rather than development, of new plants and/or new software that generally involve R\&D functions. Less immediate to quantify, but undoubtedly significant, is the improvement in the efficiency of production processes and the effectiveness of supply that such innovations make possible. Thanks to the emergence of new technologies, which are producing significant changes in the relationships between supply and demand, attention to the processes of technological innovation has grown considerably. This is mainly due to ICT, which, exploiting the various infrastructures, both old and new, offer services based on speed, interactivity and personalization of their innovative functions. ICT were initially introduced to better manage complex processes or to simplify and automate activities that required a strong and heavy human involvement. Following this logic, their role more and more evident also in the downstream healthcare processes of the introduction of new technology: no longer concerning only internal actions to improve performance, but also to external competitive programs based on a simultaneous involvement wide and diversified of both structures. In general, these organizations mostly operate with sophisticated systems in terms of quality and technology, but, at the same time, are required to collaborate within and outside public institutions for autonomy and participation in order to achieve the highest levels of integration (clashing many times with the relative intrinsic Digital Divide of the public apparatus). The combination of all these factors leads to describe the entire NHS as a complex network, both in terms of the number of nodes and the connec- 
tions/relationships between them. The socio-demographic characteristics of the population, the scarcity of available resources and the quality of health care are a further lever to develop new ways of providing healthcare services. The creation of a highly integrated system requires sudden changes, and the application of new technologies could help for a better balance between a higher quality of care and conscious use of available resources. Thus, the Italian NHS can then be seen as a non-linear system, showing a divergent behaviour as summarized in the following Figure 1, where individual actors have the opportunity to exchange information and data within the whole system and whereby the patient is necessarily the focus of communication. It benefits from the different services provided by the other actors involved (Haux, 2006).

Besides the difficult conceptual representation of the system, and the impossibility to foresee the temporal evolutions (at least with deterministic methods), the figure represents further difficulties of communication that exist among the different subjects present. Very often it happens that the various sectors of the NHS do not speak the same language or, what is worse, do not share data and information indispensable for the optimization of the single jobs. As you can see in Figure 2, only the patient communicates with the other actors of the NHS. For example, there is almost no direct exchange of information, or data, between primary care physicians and hospitals, and this creates dangerous redundancies.

Each network remains practically disconnected from the whole system and works on data collected asynchronously with the system itself. This will surely lead to a big waste of resources and a basic inefficiency (due, for example, to the presence of discordant data referred to the same subject but recovered in different moments and places) that will make the patient more and more skeptical

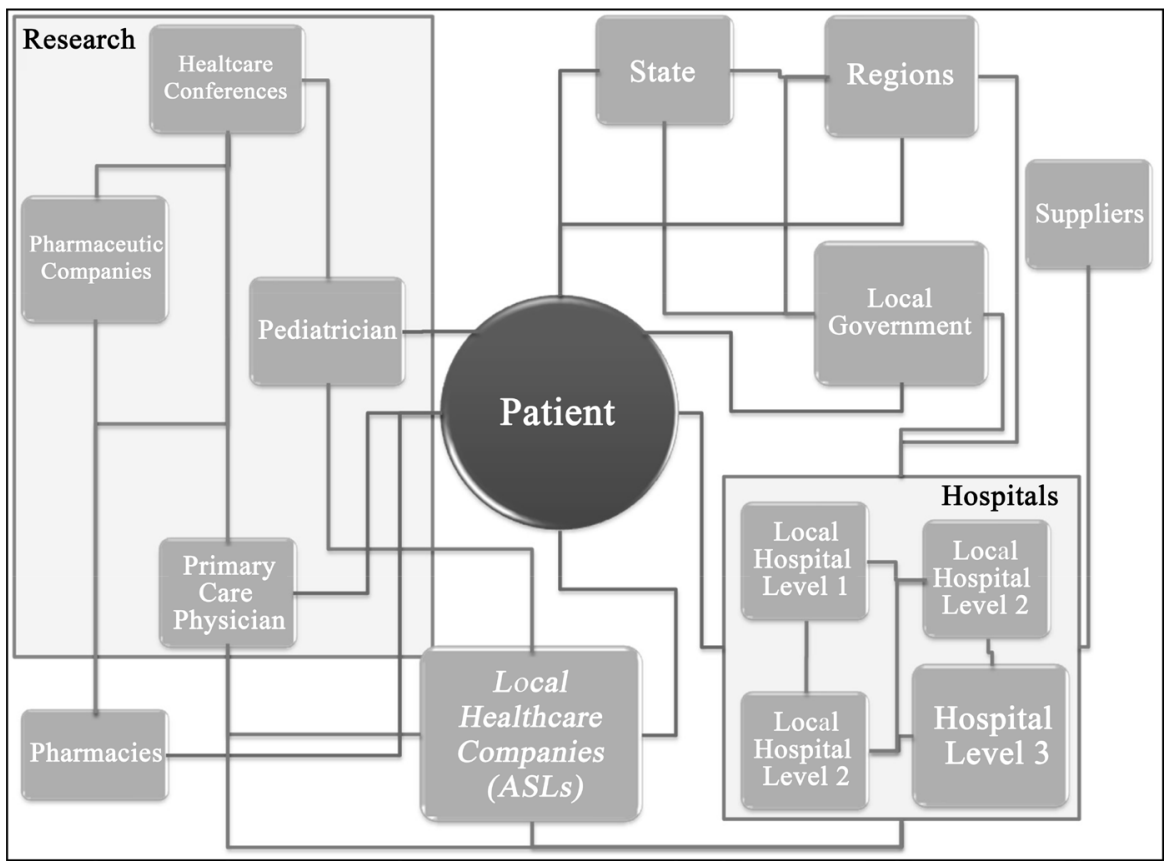

Figure 1. The network of actors in the national health system infrastructure. 


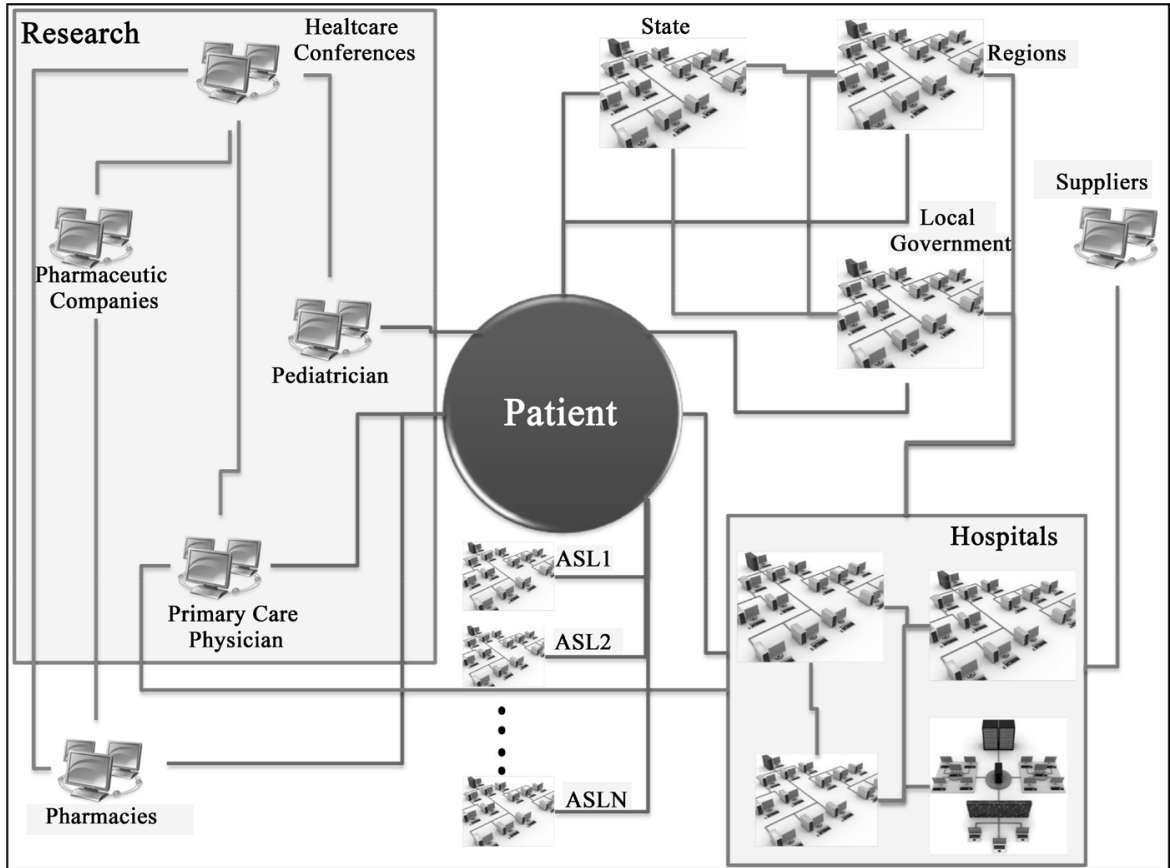

Figure 2. National health system infrastructure as a system of services.

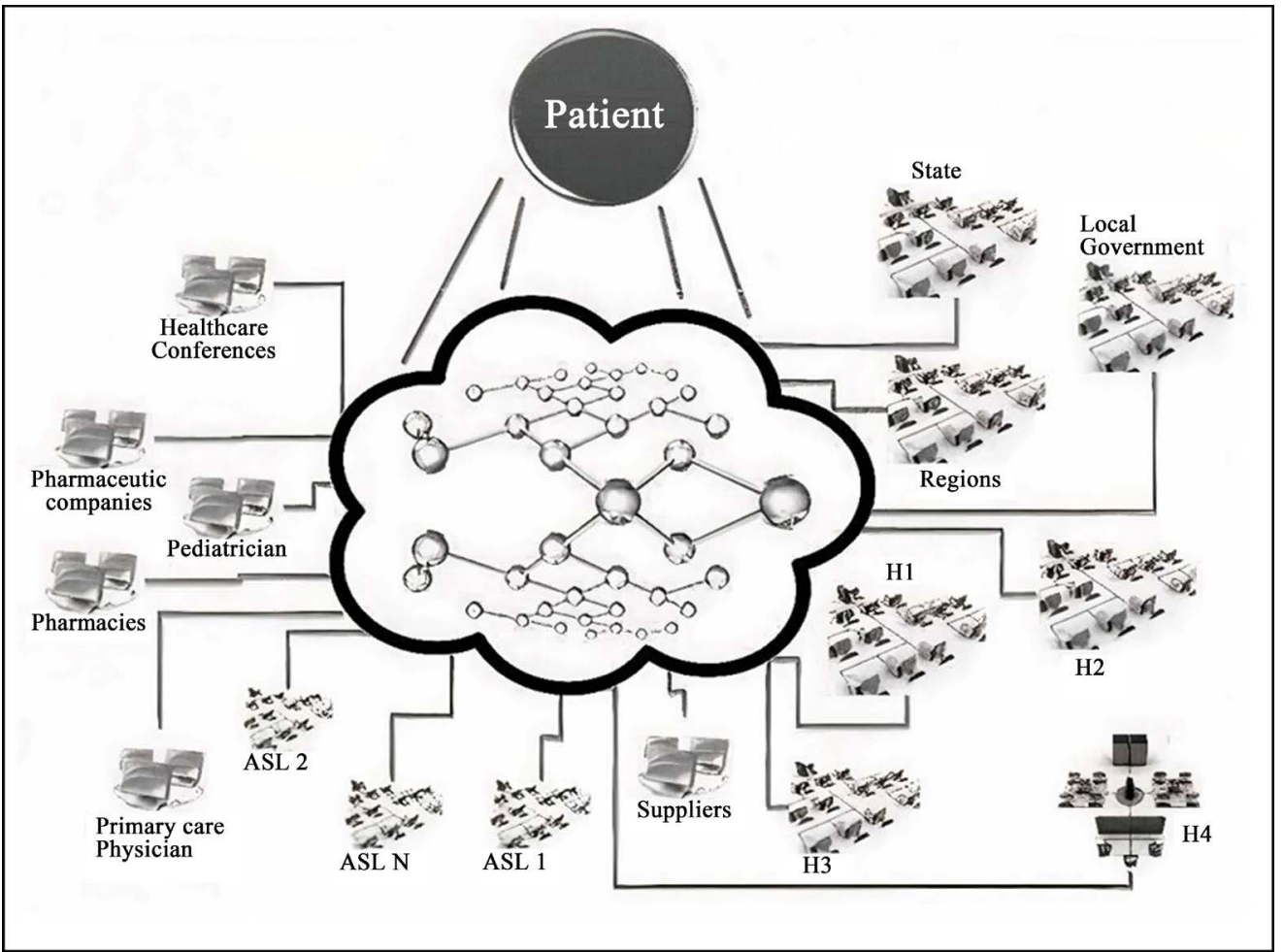

Figure 3. Infrastructure and network of actors in the national health system.

towards the whole NHS over time. A virtuous system should integrate all information at the infrastructure level and, thus, optimize the efforts of individual actors. A representation of this idea is shown in Figure 3, illustrating the patient at the center as able to interact easily with the NHS. Connection between the 
networks previously considered independent are shown too.

In summary, new technologies are enabling the shift from interpersonal to human-machine relationships and influencing customer perceptions of QoS (Cantrill, 2010). However, in order for customers/patients to really make the transition from traditional to advanced modes of operation, it is necessary that they accept to use these innovations, or better learn how to use them, and come to fully enjoy their incremental benefits. In other words, they must see technology as a mean to enhance their ability to use services and not the other way around, and as is the case in most cases, when they are assessed as too difficult to implement or sometimes even complex to understand and interpret. Organizations that invest in technological infrastructures and innovation must, however, consider other important factors, such as the psychological characteristics of clients (values, needs and motivations) and their relative initial socio-cultural gap in terms of learning dynamics, the benefits sought (use, risk and perception), the intrinsic characteristics of purchase/use (market, social rules, etc.) but, above all, the contextual technological maturity.

Although some issues related to innovation and technological services emerge, it is important to further emphasize the fundamental role of the patient / co-producer of value, enabled by the new technological solutions, but also of the different subjects belonging to the system itself and their coordination, which can be optimized thanks to ICT.

\section{Discussions}

Considering reflections on service orientation and systemic vision in the health sector, it seems appropriate to understand how the processes of co-creation of value can be managed or mediated, in order to make the health supply sustainable, channelling it towards the development of innovation and the constant search for new smart solutions in the medical field. Medicine, as well as the advancement of medical care and treatment, is based on technological progress, scientific research and innovation. Innovation in the context of healthcare is the result of both scientific and technological progress, and more often the result of mutual inferences between the two. Indeed, innovation in medicine is the result of both biomedical research (in fields including genomics, neuroscience, molecular oncology) and technology (e.g. medical diagnostics, biotechnology, health informatics, electronic devices). Technological developments in healthcare are capable of deeply shaping and transforming medical outcomes as well as patient care and treatment processes. At the same time, innovation and technology transfer can have heavy repercussions on healthcare services, which are consequently reflected by the managerial, organizational (Thakur et al., 2012) and operational needs of modern healthcare systems, with a relevant impact on healthcare costs as well. On the other hand, how can we not state that the management of health care organizations is mainly focused on innovation management? Therefore, innovation and the management dimension of health care services 
are factors highly interconnected with each other. In this framework, we can observe how the issue of sustainability of a health system requires efficient governance models and practices. Ultimately, the management of healthcare organizations, as asserted by systemic theories, is relevant to the dynamic and progressive re-orientation of the priorities of each actor involved towards the sustainability and viability of the entire system. In other words, the sustainability of health systems depends on the ability to govern the entry and implementation of the results of innovative technologies, both in clinical practice and science. Thus, although influential existing skills can achieve short-term success, innovating through incremental advancements, based on available knowledge, can become an obstacle to an organization's long-term profitability (Barile, 2009) and competitive advantage. Innovation, in fact, can bring substantial benefits both for economic variables (albeit in the long run) and for qualitative ones, such as the training of professionals in the field, or even in lifelong learning projects, aimed at ensuring a high level of quality of performance. However, in order to achieve these results, one can rarely limit oneself to innovations and scientific advances of limited scope, but must aim for radical innovations, decisive advances in knowledge (Cheng et al., 2016). In other words, the effectiveness and efficiency of new technologies are guaranteed by the pursuit of technological advances. However, implanting a technology is something complex, even more in healthcare, as this is a turbulent and challenging environment (Castiaux, 2012) but also sensitive for the crucial purpose of improving human health. Indeed, solutions must be scalable, replicable and versatile to respond to different operational scenarios and different users (Carrubbo et al., 2013). Thus, all stakeholders earn from technology advancement, implementation, and transfer. Ultimately, technologies applied to healthcare settings facilitate the generation of a high amount of information through the collection, recording, and processing of data as well as from dissemination models. The results appear to be encouraging, but the challenge still concerns the ability to fully exploit the potential. At the organizational level, this approach implies the creation of a collaboration between actors, of a relational culture that favors the integration of resources and the synergy between the multiple actors involved. In this perspective, innovation networks can be represented as inter-organizational networks that should be managed in a suitable way in order to bring adequate and satisfactory results (Landsperger et al., 2012). To date, such transfers and integrations of technology aimed at making health systems smarter ensure better, faster and more detailed performance among the actors involved, reducing errors and inefficiencies of the transfer, allowing the system to detect, manage and transform data into useful information in real time. In order to deepen the new reflections on the concept of smart (Spohrer \& Demirkan, 2015), which is the English acronym of Specific, Measurable, Agreed, Realistic and Timely, researchers have recently investigated all potential service applications, referring to the practical evidence of something that was truly iterative, interactive, interconnected, intelligent. Considering a real 
overview, they attempted to understand how to realize the sustainable development of a complex system, characterized by many actors (workers, citizens, producers, suppliers, authorities, consumers, users, pensioners, etc.) and many facilitators (for retail, roads, networks, agriculture, financial services, health, government), which are fundamental for the improvement of management capabilities and implementation of collaborative strategies. Thus, the rationale of service systems comes not from intuition or randomness, but from systematic methods, continuous learning, timely data collection, rational innovation, social responsibility, and network governance.

By applying intelligent service, intelligent practices, in intelligent organizations, through intelligent operations, for intelligent results (Troisi et al., 2019a), some important changes can occur in our daily lives.

\section{Concluding Reflections and Theoretical and Managerial Implications}

Smart networks and solutions, with different practical applications, are able to serve systems and customers better. It is, therefore, interesting to understand what are the main characteristics of a service to be considered today within intelligent systems in a hypothetical overview. Considering a real overview, we wanted to understand how to achieve the sustainable development of a system as a whole, characterized by many actors (workers, citizens, producers, suppliers, authorities, consumers, users, etc.) and many facilitators/enablers (for connections, roads, networks, financial services, assistance, government), which are essential for the improvement of the ability to manage and implement collaborative strategies. In this sense, the intelligence of service systems (especially in healthcare) does not come from intuition or randomness, but from systematic methods, continuous learning, timely data collection, rational innovation, social accountability, and network governance. By applying smart service, smart practices, embedded in smart cities, with smart organizations, through smart operations, for smart outcomes, some important changes in our daily living can occur. Also, we can note that decisions are very much influenced by data today, highlighting the importance of new content processing and feedback analysis; in fact, managers (for the public or private sector) are able to make more informed decisions, exactly as observed in PE. Considering the increasing relevance of intangibility in all transactions, every flow appears digital. Within a society in which the population is constantly growing and, therefore, needs efficient infrastructures and services (such as transport, health, education, traffic organization and public safety), we must necessarily implement useful services to simplify public management by promoting the evolution of a citizen-centric government and in the specific case of patient-centric Healthcare. In a logic more service-oriented strictly, the final value of health is co-created through shared activities, incorporating the contribution of all actors, which can thus be defined as endogenous. At the same time, the actors involved can be identified as dynamic, 
active resources, and sources of competitive advantage for the health care organization, as well as sources of innovation for the entire health service eco-system. The provider/user relationship has changed everywhere, including in Healthcare. In Healthcare it is possible to see all the main fundamentals of Service Research applied, actors are considered as integrators of resources, or as entities that exchange resources and benefit from that exchange. In practice, value is not exchanged but perceived and, therefore, also co-created by the consumer and this process is realized when the offer is transformed and subsequently consumed. The service results in the satisfaction and mutual benefit of the actors involved, especially when it comes to the most valuable asset for a community, the protection of health. This is how Smart Healthcare is born. Once this interdependence is appreciated and shared, it seems inevitable to conceive the health service as the result of collaboration between actors aiming at the creation of a shared value, such as that of public health. An effective and efficient management of care becomes truly fundamental, it is neither linked to statistical results nor an internal matter of the organization itself, but it indirectly affects the eco-system of health service as a whole. The problems that plague our healthcare system are many and often too long-lasting: Rising costs, limited access to information, difficulty in responses, the slow cycle of development of new treatments. In addition, the components, processes, and people that are part of the healthcare system are not always coordinated. Duplication and errors occur due to manual processes and inaccessible data. Smarter healthcare starts with better communication, more detailed and faster, able to manage relevant information in real time. Solutions must be replicable, scalable and versatile across many different contexts to be truly useful. This smarter approach in healthcare uses information to create new knowledge. Practitioners, researchers, and all players in the service eco-system can work better thanks to a more detailed and comprehensive view of patient data. Ultimately, it is desirable that health service systems can be considered as a positive-sum cooperative game aimed at promoting, implementing, and coordinating the contributions of multiple actors. Therefore, the goal is to provide a health care system in which State, Regions, Universities, Businesses and individuals work together to improve the conditions of viability, sustainability, effectiveness and efficiency of health value.

Strengthening relationships in healthcare requires an increasingly significant involvement of stakeholders (defined as empowerment) and mutual recognition by continuity. This means, in terms of management, that an inter-systemic effort aimed at achieving and promoting effective integration in a sustainable logic of mutual benefit. The diversity of actors (patients, physicians, nurses, hospitals, researchers) is a strength; it allows the integration of complementary resources and promotes the dissemination of knowledge.

All this obviously requires, at the macro level, the coordination of governance, management and social systems, and therefore the introduction of strong interaction mechanisms, in order to make the service more contemporary, beyond 
sequential exchange, but rather more interactive and collaborative.

\section{Conflicts of Interest}

The authors declare no conflicts of interest regarding the publication of this paper.

\section{References}

Baldwin, C. Y., Clark, K. B., \& Clark, K. B. (2000). Design Rules: The Power of Modularity (Vol. 1). Cambridge, MA: MIT Press.

https://doi.org/10.7551/mitpress/2366.001.0001

Barile, S. (2009). Management sistemico vitale (Vol. 1). Giappichelli.

Barile, S., Grimaldi, M., Loia, F., \& Sirianni, C. A. (2020). Technology, Value Co-Creation and Innovation in Service Ecosystems: Toward Sustainable Co-Innovation. Sustainability, 12, 2759. https://doi.org/10.3390/su12072759

Cantrill, S. V. (2010). Computers in Patient Care: The Promise and the Challenge. Communications of the ACM, 53, 42-47. https://doi.org/10.1145/1810891.1810907

Capra, F. (2002). Complexity and Life. Emergence, 4, 15-33. https://doi.org/10.1207/S15327000EM041\&2-03

Carrubbo, L., Clarizia, F., Hisa, X., \& Bilotta, A. (2013). New “Smarter" Solutions for the Healthcare Complex Service System. In E. Gummesson, C. Mele, \& F. Polese (Eds.), System Theory and Service Science: Integrating Three Perspectives in a New Service Agenda (pp. 1-23). Napoli: Giannini.

Castiaux, A. (2012). Developing Dynamic Capabilities to Meet Sustainable Development Challenges. International Journal of Innovation Management, 16, Article ID: 1240013. https://doi.org/10.1142/S1363919612400130

Chakraborty, S., \& Dobrzykowski, D. D. (2013). Supply Chain Practices for Complexity in Healthcare: A Service-Dominant Logic View. IUP Journal of Supply Chain Management, 10, 53-75.

Cheng, C. C., Yang, C., \& Sheu, C. (2016). Effects of Open Innovation and Knowledge-Based Dynamic Capabilities on Radical Innovation: An Empirical Study. Journal of Engineering and Technology Management, 41, 79-91. https://doi.org/10.1016/j.jengtecman.2016.07.002

Ciasullo, M. V., Maione, G., Torre, C., \& Troisi, O. (2017). What about Sustainability? An Empirical Analysis of Consumers' Purchasing Behaviour in Fashion Context. Sustainability, 9, 1617. https://doi.org/10.3390/su9091617

Cooper, P. (2014). Data, Information, Knowledge and Wisdom. Anaesthesia \& Intensive Care Medicine, 15, 44-45. https://doi.org/10.1016/j.mpaic.2013.11.009

Crespo Garrido, M. J., Grimaldi, M., Maione, G., \& Vesci, M. (2017). Inside Out: Organizations as Service Systems Equipped with Relational Boundaries. Systems, 5, 36. https://doi.org/10.3390/systems5020036

Gummesson, E. (1993). Quality Management in Service Organization. New York: International Service Quality Association.

Gummesson, E. (2008). Extending the Service-Dominant Logic: From Customer Centricity to Balanced Centricity. Journal of the Academy of Marketing Science, 36, 15-17. https://doi.org/10.1007/s11747-007-0065-x

Gummesson, E. (2011). Total Relationship Marketing. London: Routledge. https://doi.org/10.4324/9780080880112 
Haux, R. (2006). Health Information Systems-Past, Present, Future. International Journal of Medical Informatics, 75, 268-281. https://doi.org/10.1016/j.ijmedinf.2005.08.002

Jaakkola, E., \& Hakanen, T. (2013). Value Co-Creation in Solution Networks. Industrial Marketing Management, 42, 47-58. https://doi.org/10.1016/j.indmarman.2012.11.005

Jacobson, P. D., \& Neumann, P. J. (2009). A Framework to Measure the Value of Public Health Services. Health Services Research, 44, 1880-1896. https://doi.org/10.1111/j.1475-6773.2009.01013.x

Landsperger, J., Spieth, P., \& Heidenreich, S. (2012). How Network Managers Contribute to Innovation Network Performance. International Journal of Innovation Management, 16, Article ID: 1240009. https://doi.org/10.1142/S1363919612400099

Levitt, T. (1981). Marketing Intangible Products and Product Intangibles. Cornell Hotel and Restaurant Administration Quarterly, 22, 37-44. https://doi.org/10.1177/001088048102200209

Lovelock, C., \& Gummesson, E. (2004). Whither Services Marketing? In Search of a New Paradigm and Fresh Perspectives. Journal of Service Research, 7, 20-41.

https://doi.org/10.1177/1094670504266131

Lusch, R. F., Vargo, S. L., \& O’brien, M. (2007). Competing through Service: Insights from Service-Dominant Logic. Journal of Retailing, 83, 5-18. https://doi.org/10.1016/j.jretai.2006.10.002

Maglio, P. P., \& Spohrer, J. (2008). Fundamentals of Service Science. Journal of the Academy of Marketing Science, 36, 18-20. https://doi.org/10.1007/s11747-007-0058-9

Maglio, P. P., \& Spohrer, J. (2013). A Service Science Perspective on Business Model Innovation. Industrial Marketing Management, 42, 665-670. https://doi.org/10.1016/j.indmarman.2013.05.007

McColl-Kennedy, J. R., Vargo, S. L., Dagger, T. S., Sweeney, J. C., \& Kasteren, Y. V. (2012). Health Care Customer Value Cocreation Practice Styles. Journal of Service Research, 15, 370-389. https://doi.org/10.1177/1094670512442806

Payne, A. F., Storbacka, K., \& Frow, P. (2008). Managing the Co-Creation of Value. Journal of the Academy of Marketing Science, 36, 83-96. https://doi.org/10.1007/s11747-007-0070-0

Pellicano, M., Calabrese, M., Loia, F., \& Maione, G. (2018). Value Co-Creation Practices in Smart City Ecosystem. Journal of Service Science and Management, 12, 34-57. https://doi.org/10.4236/jssm.2019.121003

Pels, J., Polese, F., \& Brodie, R. J. (2012). Value Co-Creation: Using a Viable Systems Approach to Draw Implications from Organizational Theories. Mercati e Competitività, 1, 19-38.

Polese, F., \& Carrubbo, L. (2017). Eco-sistemi di servizio in sanità (Vol. 65). Torino: G Giappichelli Editore.

Polese, F., Carrubbo, L., Bruni, R., \& Maione, G. (2017b). The Viable System Perspective of Actors in Eco-Systems. The TQM Journal, 29, 783-799. https://doi.org/10.1108/TQM-05-2017-0055

Polese, F., Mele, C., \& Gummesson, E. (2017a). Value Co-Creation as a Complex Adaptive Process. Journal of Service Theory and Practice, 27, 926-929. https://doi.org/10.1108/ISTP-07-2017-0111

Polese, F., Troisi, O., Grimaldi, M., \& Loia, F. (2020a). Reinterpreting Governance in Smart Cities: An Ecosystem-Based View. In A. Visvizi, \& M. Lytras (Eds.), Smart Cities and the UN's SDGs (pp. 1-20). Amsterdam: Elsevier.

Polese, F., Troisi, O., Grimaldi, M., \& Sirianni, C. (2020b). Conceptualizing Social 
Change, between Value Co-Creation and Ecosystems Innovation. Marketing as a Social Science: Festschrift für Universitätsprofessor Dr. Dr. hc Helge Löbler, 203.

Prahalad, C. K. (2004). The Blinders of Dominant Logic. Long Range Planning, 37, 171-179. https://doi.org/10.1016/j.lrp.2004.01.010

Prahalad, C. K., \& Ramaswamy, V. (2004). Co-Creation Experiences: The Next Practice in Value Creation. Journal of Interactive Marketing, 18, 5-14.

https://doi.org/10.1002/dir.20015

Ramaswamy, V., \& Ozcan, K. (2018). What Is Co-Creation? An Interactional Creation Framework and Its Implications for Value Creation. Journal of Business Research, 84, 196-205. https://doi.org/10.1016/j.jbusres.2017.11.027

Spohrer, J. C., \& Demirkan, H. (2015). Introduction to the Smart Service Systems: Analytics, Cognition, and Innovation Minitrack. 2015 IEEE 48th Hawaii International Conference on System Sciences, Kauai, 5-8 January 2015, 1442. https://doi.org/10.1109/HICSS.2015.175

Spohrer, J., Vargo, S. L., Caswell, N., \& Maglio, P. P. (2008). The Service System Is the Basic Abstraction of Service Science. Proceedings of the 41st Annual Hawaii International Conference on System Sciences (HICSS 2008), Walkoloa, 7-10 January 2008, 104. https://doi.org/10.1109/HICSS.2008.451

Sweeney, J. C., Danaher, T. S., \& McColl-Kennedy, J. R. (2015). Customer Effort in Value Cocreation Activities: Improving Quality of Life and Behavioural Intentions of Health Care Customers. Journal of Service Research, 18, 318-335. https://doi.org/10.1177/1094670515572128

Thakur, R., Hsu, S. H., \& Fontenot, G. (2012). Innovation in Healthcare: Issues and Future Trends. Journal of Business Research, 65, 562-569. https://doi.org/10.1016/j.jbusres.2011.02.022

Tommasetti, A., Mussari, R., Maione, G., \& Sorrentino, D. (2020). Sustainability Accounting and Reporting in the Public Sector: Towards Public Value Co-Creation?. Sustainability, 12, 1909. https://doi.org/10.3390/su12051909

Tommasetti, A., Troisi, O., \& Vesci, M. (2017). Measuring Customer Value Co-Creation Behaviour: Developing a Conceptual Model Based on Service-Dominant Logic. Journal of Service Theory and Practice, 27, 930-950. https://doi.org/10.1108/JSTP-10-2015-0215

Troisi, O., Carrubbo, L., Maione, G., \& Torre, C. (2017). Unity Is Strength: Co-Creating Value in Working Context. Journal of Business and Economics, 8, 97-104.

Troisi, O., D’Arco, M., Loia, F., \& Maione, G. (2018a). Big Data Management: The Case of Mulino Bianco's Engagement Platform for Value Co-Creation. International Journal of Engineering Business Management, 10, 1847979018767776. https://doi.org/10.1177/1847979018767776

Troisi, O., Grimaldi, M., Loia, F., \& Maione, G. (2018b). Big Data and Sentiment Analysis to Highlight Decision Behaviours: A Case Study for Student Population. Behaviour \& Information Technology, 37, 1111-1128. https://doi.org/10.1080/0144929X.2018.1502355

Troisi, O., Maione, G., Grimaldi, M., \& Loia, F. (2019a). Growth Hacking: Insights on Data-Driven Decision-Making from Three Firms. Industrial Marketing Management, 90, 538-557. https://doi.org/10.1016/j.indmarman.2019.08.005

Troisi, O., Sarno, D., Maione, G., \& Loia, F. (2019b). Service Science Management Engineering and Design (SSMED): A Semiautomatic Literature Review. Journal of Marketing Management, 35, 1015-1046. https://doi.org/10.1080/0267257X.2019.1605402

Troisi, O., Visvizi, A., \& Grimaldi, M. (2021). The Different Shades of Innovation Emer- 
gence in Smart Service Systems: The Case of Italian Cluster for Aerospace Technology. Journal of Business \& Industrial Marketing. https://doi.org/10.1108/JBIM-02-2020-0091

Vargo, S. L., \& Lusch, R. F. (2004). Evolving to a New Dominant Logic for Marketing. Journal of Marketing, 68, 1-17. https://doi.org/10.1509/jmkg.68.1.1.24036

Vargo, S. L., \& Lusch, R. F. (2008a). From Goods to Service (s): Divergences and Convergences of Logics. Industrial Marketing Management, 37, 254-259. https://doi.org/10.1016/j.indmarman.2007.07.004

Vargo, S. L., \& Lusch, R. F. (2008b). Service-Dominant Logic: Continuing the Evolution. Journal of the Academy of Marketing Science, 36, 1-10. https://doi.org/10.1007/s11747-007-0069-6

Vargo, S. L., \& Lusch, R. F. (2017). Service-Dominant Logic 2025. International Journal of Research in Marketing, 34, 46-67. https://doi.org/10.1016/j.ijresmar.2016.11.001

Vargo, S. L., Lusch, R. F., \& Koskela-Huotari, K. (2018). The SAGE Handbook of Service-Dominant Logic. London: Sage. https://doi.org/10.4135/9781526470355

Womack, J. P., Jones, D. T., \& Roos, D. (2007). The Machine That Changed the World: The Story of Lean Production-Toyota's Secret Weapon in the Global Car Wars That Is Now Revolutionizing World Industry. New York: Simon and Schuster. 